\title{
POPULASI DAN KARAKTERISASI FENOTIP KANTONG SEMAR (Nepenthes spp.) DI TAMAN KEANEKARAGAMAN HAYATI HUTAN PELAWAN KABUPATEN BANGKA TENGAH, PROVINSI KEPULAUAN BANGKA BELITUNG
}

\section{(Pupulation and Phenotive Characterization of Pitcher Plant (Nepenthes spp.) in Pelawan Forest Biodiversity Park at Central Bangka Regency, Bangka Belitung Islands Province)}

\author{
ARMANDA ${ }^{1)}$, ANGGRAENI $^{1 *}$ DAN TRI WAHYUNI ${ }^{2)}$ \\ 1) Program Studi Biologi Fakultas Pertanian Perikanan dan Biologi Universitas Bangka Belitung, Provinsi Kepulauan \\ Bangka Belitung, Indonesia 33172 \\ 2) Balai Perencanaan Pembangunan dan Penelitian Pengembangan Daerah Bangka Tengah, Indonesia 33181
}

*Email: anggieib@gmail.com

Diterima 09 Desember 2019 / Disetujui 27 April 2020

\begin{abstract}
Pitcher plant (Nepenthes spp.) is the one of carnivorous plant that can trap insects and other small species. The diversity of Nepenthes spp. comprises about 139 species throughout its distribution in the world. In Bangka Belitung Province, Nepenthes spp. found in Pelawan Forest Biodiversity Park has never been reported. This study aimed to record the population of each species and characterize the phenotive of Nepenthes spp. The data were collected by purposive sampling method. The diversity of Nepenthes spp. The results found 3 species, namely Nepenthes gracilis Korth consist of 348 individuals, Nepenthes rafflesiana Jack consist of 18 individuals and Nepenthes ampullaria Jack consist of 45 individuals. The diversity index $\left(H^{\prime}\right)$ of 0.36 and classified as low. The phenotive characteristics of sterile leaves from 2-37 strands, fertile leaves from 1-12 strands, leaf length from 9.5-37.2 cm, leaf width from 1.7-8.2 cm and leaf thickness from 2,1-3,6 mm. The length of the pitcher ranges from 3.4-22.2 cm and the diameter from 1.6-4.4 cm. Variations shape of the pitcher is a long neck jug, pitcher jug, long trumpet, and chubby glass. Variations style of the pitcher is red spots, wings and lace vary, winged and lace top pitcher, pitcher covers consisting of proportional and disproportional shapes. The length of the stem ranges from 44-550 cm, the diameter of the stem ranges from 7.0-8.5 mm and the length of the tendrils ranges from $1.0-34.4 \mathrm{~cm}$. The tendril position consists of back, beside and in front of the pitcher.
\end{abstract}

Keywords: diversity, fenotive characterizations, Nepenthes spp.

\section{ABSTRAK}

Kantong semar (Nepenthes spp.) merupakan tumbuhan yang mampu menjebak serangga dan binatang kecil lainnya. Tercatat sebanyak 139 jenis tersebar di Asia Tenggara. Di provinsi Bangka Belitung, Nepenthes spp. ditemukan di Taman Keanekaragaman Hayati Hutan Pelawan. Informasi data mengenai karakteristik fenotif dan habitat Nepenthes spp. belum pernah dilaporkan. Tujuan penelitian yaitu mendata jumlah populasi dari masing-masing jenis dan mengkarakterisasi fenotip Nepenthes spp. Metode pengambilan data menggunakan teknik purposive sampling. Hasil penelitian menemukan 3 spesies yaitu Nepenthes gracilis Korth dengan populasi sebanyak 348 individu, Nepenthes rafflesiana Jack dengan populasi sebanyak 18 individu dan Nepenthes ampullaria Jack dengan populasi sebanyak 45 individu. Indeks keanekaragaman (H') sebesar 0,36 dan tergolong rendah. Karakteristik fenotif jumlah daun steril berkisar 2-37 helai, daun fertil berkisar 1-12 helai, panjang daun berkisar 9,5-37,2 cm, lebar daun berkisar 1,7-8,2 cm dan tebal daun berkisar 2,1-3,6 mm. Panjang kantong berkisar 3,4-22,2 cm dan diameter kantong berkisar 1,6-4,4 $\mathrm{cm}$. Bentuk silinder (gracilis), tempayan (ampullaria), terompet (rafflesiana kantong atas), bulat telur (rafflesiana kantong bawah). Variasi corak kantong berupa bintik-bintik merah, sayap dan renda bervariasi, kantong atas tidak bersayap, yang bersayap umumnya kantong bawah dan berrenda, tutup kantong terdiri atas bentuk proporsional dan tak proporsional. Panjang batang berkisar 44-550 cm, diameter batang berkisar 7,0-8,5 mm dan panjang sulur berkisar 1,0-34,4 cm. Posisi sulur terdiri atas posisi membelakangi, menyamping dan di depan mulut kantong.

Kata kunci: karakteristik fenotif, keanekaragaman, Nepenthes spp.

\section{PENDAHULUAN}

Kantong semar (Nepenthes spp.) merupakan tumbuhan karnivora yang mampu menjebak serangga dan hewan kecil lainnya, organ tersebut berupa kantong (Mansur 2012). Di Indonesia ditemukan sebanyak 64 spesies Nepenthes spp. (Handoyo dan Sitanggang 2006). Khususnya di Provinsi Kepulauan Bangka Belitung terdapat lima jenis murni dan dua jenis hasil persilangan alami (Rizqiani 2018).
Nepenthes spp. memiliki keunikan sehingga dijadikan tanaman hias di Indonesia. Keunikan yang menjadikan Nepenthes spp. sebagai tanaman hias yaitu bentuk dan warna kantong yang bervariasi. Keragaman morfologi dapat digunakan untuk pengelompokkan antar spesies kantong semar (Selviana et al. 2018). Keragaman morfologi juga dapat disebabkan faktor lingkungan yang turut mempengaruhi perubahan morfologi Nepenthes spp.. Kondisi lingkungan yang berbeda mengakibatkan 
perubahan pola morfologi tumbuhan sehingga akan terbentuk sifat-sifat yang berbeda (Selviana et al. 2018).

Provinsi Kepulauan Bangka Belitung khususya Kabupaten Bangka Tengah terdapat Taman Keanekaragaman Hayati Hutan Pelawan yang di dalamnya terdapat Nepenthes spp. tergolong dalam hutan hujan dataran rendah yang memiliki habitat yang berbeda dengan hutan kerangas. Kissinger (2013) menyatakan bahwa salah satu informasi penting yang diperlukan untuk mendukung pengelolaan yang baik terhadap sumberdaya tumbuhan yaitu teridentifikasikannya karakteristik habitat dan fenotif, sehingga akan menjadi dasar bagi tindakan konservasi. Kelengkapan informasi merupakan faktor yang penting dalam menyusun rencana konservasi dan strategi pengelolaan sumber daya alam hayati (Sartika 2017). Informasi data mengenai karakteristik fenotip dan habitat Nepenthes spp. khususnya di Taman Keanekaragaman Hayati Hutan Pelawan belum pernah dilaporkan sehingga perlu adanya penelitian untuk mendukung upaya konservasi. Tujuan penelitian yaitu mendata jumlah populasi dari masingmasing jenis dan mengkarakterisasi fenotip Nepenthes spp. di Taman Keanekaragaman Hayati Hutan Pelawan.

\section{METODE PENELITIAN}

Penelitian dilaksanakan di Taman Keanekaragaman Hayati Hutan Pelawan, Desa Namang, Kabupaten Bangka Tengah pada Juni sampai Agustus 2019. Penelitian menggunakan metode jelajah dengan pengamatan objek penelitian yaitu dengan plot berukuran 20 x 20 meter sebanyak empat plot yang diletakkan secara purposive sampling. Bahan yang digunakan yaitu alkohol $70 \%$. Alat yang digunakan terdiri atas alat tulis, buku munsell color chart for plant tissues, global positioning system (GPS), kamera digital, penggaris, peralatan herbarium, pita meter. Pengamatan karakter fenotip meliputi daun, kantong, batang dan sulur (Tabel $1)$.

Tabel 1 Objek pengamatan dan parameter

\begin{tabular}{lll}
\hline Objek pengamatan & \multicolumn{1}{c}{ Parameter } \\
\hline \multirow{2}{*}{ Pengamatan daun } & 1. Jumlah daun fertil (memiliki kantong) dan steril (tidak memiliki kantong) \\
& 2. Ukuran daun (panjang, lebar dan tebal) \\
\multirow{2}{*}{ Pengamatan kantong } & 1. Ukuran kantong (panjang dan diameter) \\
& 2. & Bentuk kantong \\
\multirow{2}{*}{ Pengamatan batang } & 3. Warna kantong (badan, sayap, bibir, tutup) \\
& 4. Corak kantong, status sayap dan renda, bentuk kantong \\
\hline \multirow{2}{*}{ Pengamatan sulur } & 1. Ukuran (paniang dan diameter) \\
& 2. Bentuk batang \\
\hline
\end{tabular}

Analisis data keanekaragaman Nepenthes spp. dilakukan menggunakan indeks Shannon-Wiener sebagai berikut (Odum 1993):

Keterangan:

$$
H^{\prime}=-\sum(n i / N) \log (n i / N)
$$

H' : Indeks keanekaragaman;

ni : Jumlah individu spesies (i);

$\mathrm{N}$ : Jumlah individu seluruh spesies.

\section{HASIL DAN PEMBAHASAN}

\section{Populasi Nephentes spp.}

Hasil inventarisasi diketahui ada tiga jenis Nepenthes spp. yaitu N. gracilis Korth sebanyak 348 individu, $N$. rafflesiana Jack sebanyak 18 individu, $N$. ampullaria Jack sebanyak 45 individu dari total luas plot seluas $1.600 \mathrm{~m}^{2}$ (Tabel 2). Jumlah populasi $N$. gracilis lebih banyak ditemukan dari jenis lainnya hal ini diduga karena jenis tersebut memiliki daya adaptasi yang lebih tinggi. Hal tersebut sesuai dengan pernyataan Syamsi dan Sudirman (2017) yang menyatakan bahwa $N$. gracilis mempunyai daya adaptasi yang lebih tinggi dari jenis lainnya. Penelitian Rizqiani (2018) menunjukkan bahwa $N$. gracilis merupakan jenis yang paling banyak ditemukan di Provinsi Kepulauan Bangka Belitung. Mansur (2008) menambahkan bahwa N. gracilis memiliki daerah sebaran yang luas.

Keanekaragaman Nepenthes spp. di lokasi penelitian tergolong rendah $\left(\mathrm{H}^{\prime}\right)=0,39$ (Tabel 2). Hal ini serupa dengan hasil penelitian Gultom et al. (2015) di Kawasan Konservasi Rumah Pelangi, Dusun Gunung Benuah, Kecamatan Sungai, Ambawang Kabupaten Kubu Raya. Penelitian Zakaria et al. (2016) juga menunjukkan indeks keanekaragaman Nepenthes spp. di Kawasan Hutan Lindung Gunung Semahung, Desa Saham, Kecamatan Sengah Temila, Kabupaten Landak tergolong rendah. Rendahnya keanekaragaman spesies Nepenthes spp. diduga karena sedikitnya jumlah spesies yang ditemukan. 


\section{Karakterisasi Fenotip}

\section{a. Variasi daun}

Jumlah dauh fertil dan steril kantong atas $N$. gracilis dan $N$. ampullaria lebih banyak dibandingkan kantong bawah, sedangkan jumlah daun fertil dan steril daun kantong atas $N$. rafflesiana lebih sedikit dibandingkan dengan daun kantong bawah (Tabel 3). Jumlah daun steril $N$. ampullaria lebih banyak dari jumlah daun fertil (Tabel 3). Hal ini diduga bahwa di lokasi penelitian lebih banyak ditemukan $N$. ampullaria dewasa yang merambat pada tumbuhan di sekitarnya. Handayani et al. (2005) memperkuat bahwa Nepenthes spp. dewasa lebih banyak memiliki daun steril dibandingkan dengan daun fertil.

\section{b. Variasi kantong}

Bentuk kantong N. gracilis yaitu silinder di bagian atas dan bulat telur di bagian bawah. Bentuk kantong atas $N$. rafflesiana yaitu terompet berleher panjang, sedangkan kantong bawah berbentuk gelas tambun. $N$. ampullaria memiliki kantong berbentuk gelas tambun (Tabel 4). Hal ini sama dengan penelitian Alfionita (2018); Devilia (2018) yang menemukan bentuk kantong atas $N$. gracilis yaitu kendi leher panjang dan kantong bawahnya yaitu kendi leher panjang atau kendi gentong, bentuk kantong atas $N$. rafflesiana yaitu terompet panjang dan kantong bawahnya yaitu gelas tambun, bentuk kantong atas dan bawah $N$. ampullaria yaitu gelas tambun. Selviana et al. (2018) menyatakan bahwa perbedaan ukuran dan bentuk kantong disebabkan perbedaan perawakan tiap jenis. Jenis Nepenthes yang berbeda memiliki karakter kantong yang berbeda pula
(Ginting dan Lubis 2017). Handayani et al. (2005) memperkuat bahwa bentuk kantong atas yang lebih ramping dan ringan bertujuan untuk tahan terhadap tiupan angin. N. ampullaria umumnya memiliki kantong bawah yang banyak dan bergerombol (Gusdiarto et al. 2018), namun jarang ditemukan adanya kantong atas (Jeeb dan Cheek 2001; Setiawan 2013).

Warna kantong Nepenthes spp. yang ditemukan bervariasi, sama dengan hasil penelitian Syamsi dan Sudirman (2017) yang menemukan warna badan, sayap, bibir dan tutup kantong berwarna hijau kuning, hijau kuning bercak merah dan merah (Tabel 5). Hal ini diduga warna kantong Nepenthes spp. setiap jenis tidak jauh berbeda. Penelitian Cahyono et al. (2019) di Pulau Halmahera juga menemukan 2 variasi warna yaitu hijau dan hijau bercak merah. Adanya corak dan warna yang menarik dari kantong diduga sebagai strategi Nepenthes spp. dalam menarik serangga. Hal ini sesuai dengan pendapat Mulyanto et al. (2000); Handayani dan Astuti (2005) yang menyatakan bahwa warna kantong yang cerah sebagai upaya untuk menarik mangsanya.

Kantong atas dan bawah $N$. ampullaria memiliki sayap dan renda, sedangkan sayap dan renda kantong atas $N$. gracilis dan $N$. rafflesiana tidak ditemukan. Handayani dan Astuti (2005) sependapat bahwa kantong bawah memiliki sayap kantong dengan renda yang bertujuan untuk memudahkan serangga tanah untuk masuk kedalam kantong, namun kantong atas umumnya tak memiliki sayap karena umumnya serangga yang terjebak adalah serangga yang terbang.

Tabel 2 Populasi Nephentes spp.

\begin{tabular}{lccccc}
\hline \multirow{2}{*}{ Spesies } & \multicolumn{3}{c}{ Jumlah individu } & \multirow{2}{*}{ Kerapatan (ind/ha) } & \multirow{2}{*}{ Indeks keanekaragaman } \\
\cline { 2 - 4 } N. gracilis & Habitat kering & Habitat basah & Total & & \multirow{2}{*}{0,39} \\
N. rafflesiana & 342 & 6 & 348 & 2.177 & 110 \\
N. ampularia & 17 & 1 & 18 & 279 & \\
\hline
\end{tabular}

Tabel 3 Morfologi daun Nephenthes spp.

\begin{tabular}{|c|c|c|c|c|c|c|c|}
\hline \multirow{2}{*}{ Spesies } & \multirow{2}{*}{ Habitat } & \multirow{2}{*}{ Status } & \multicolumn{2}{|c|}{ Jumlah daun } & \multicolumn{3}{|c|}{ Ukuran daun } \\
\hline & & & Steril & Fertil & $\mathrm{P}(\mathrm{cm})$ & $\mathrm{L}(\mathrm{cm})$ & $\mathrm{T}(\mathrm{mm})$ \\
\hline \multirow{4}{*}{ N. gracilis } & \multirow[b]{2}{*}{$\mathrm{K}$} & $\mathrm{ka}$ & 21 & 9 & 14,9 & 4,2 & 3,1 \\
\hline & & $\mathrm{kb}$ & 3 & 7 & 11,5 & 2,2 & 3,1 \\
\hline & \multirow{2}{*}{ B } & $\mathrm{ka}$ & 20 & 12 & 14,0 & 2,4 & 2,6 \\
\hline & & $\mathrm{kb}$ & 2 & 7 & 9,5 & 1,7 & 2,3 \\
\hline \multirow{4}{*}{ N. rafflesiana } & \multirow{2}{*}{$\mathrm{K}$} & $\mathrm{ka}$ & 9 & 9 & 26,3 & 4,7 & 3,6 \\
\hline & & $\mathrm{kb}$ & 18 & 7 & 37,2 & 6,1 & 3,4 \\
\hline & \multirow[b]{2}{*}{ B } & $\mathrm{ka}$ & 4 & 9 & 28,3 & 4,2 & 2,7 \\
\hline & & $\mathrm{kb}$ & 5 & 10 & 30,6 & 5,3 & 2,9 \\
\hline \multirow{4}{*}{ N. ampullaria } & \multirow{2}{*}{$\mathrm{K}$} & $\mathrm{ka}$ & 37 & 3 & 29,8 & 8,2 & 2,1 \\
\hline & & $\mathrm{kb}$ & 6 & 1 & 24,0 & 5,3 & 2,1 \\
\hline & \multirow{2}{*}{ B } & $\mathrm{ka}$ & 19 & 4 & 33,8 & 7,7 & 2,3 \\
\hline & & $\mathrm{kb}$ & 12 & 2 & 28,2 & 6,9 & 2,1 \\
\hline
\end{tabular}

Keterangan: K: kering; B: basah; ka: daun kantong atas; kb: daun kantong bawah; P: panjang; L: lebar; T: tebal. 
Tabel 4 Variasi bentuk kantong

\begin{tabular}{|c|c|c|c|c|c|c|}
\hline \multirow{2}{*}{ Spesies } & \multirow{2}{*}{ Habitat } & \multirow{2}{*}{ Status } & \multicolumn{4}{|c|}{ Bentuk kantong } \\
\hline & & & KLP & KG & TP & GT \\
\hline \multirow{4}{*}{ N. gracilis } & \multirow{2}{*}{ K } & $\mathrm{ka}$ & $\sqrt{ }$ & - & - & - \\
\hline & & $\mathrm{kb}$ & - & $\sqrt{ }$ & - & - \\
\hline & \multirow{2}{*}{ B } & $\mathrm{ka}$ & $\sqrt{ }$ & - & - & - \\
\hline & & $\mathrm{kb}$ & - & $\sqrt{ }$ & - & - \\
\hline \multirow{4}{*}{ N. rafflesiana } & \multirow{2}{*}{ K } & $\mathrm{ka}$ & - & - & $\sqrt{ }$ & - \\
\hline & & $\mathrm{kb}$ & - & - & - & $\sqrt{ }$ \\
\hline & \multirow{2}{*}{ B } & $\mathrm{ka}$ & - & - & $\sqrt{ }$ & - \\
\hline & & $\mathrm{kb}$ & - & - & - & $\sqrt{ }$ \\
\hline \multirow{4}{*}{ N. ampullaria } & \multirow{2}{*}{$\mathrm{K}$} & $\mathrm{ka}$ & - & - & - & $\sqrt{ }$ \\
\hline & & $\mathrm{kb}$ & - & - & - & $\sqrt{ }$ \\
\hline & \multirow[b]{2}{*}{ B } & $\mathrm{ka}$ & - & - & - & $\sqrt{ }$ \\
\hline & & $\mathrm{kb}$ & - & - & - & $\sqrt{ }$ \\
\hline
\end{tabular}

Keterangan: K: kering; B: basah; KLP: kendi leher panjang; KG: kendi gentong; TP: terompet panjang; GT: gelas tambun; ka: kantong atas; kb: kantong bawah; $\sqrt{ }$ : memiliki; - : tidak memiliki.

Tabel 5 Warna, status corak, sayap, renda dan bentuk tutup kantong.

\begin{tabular}{|c|c|c|c|c|c|c|c|c|c|c|}
\hline \multirow{2}{*}{ Spesies } & \multirow{2}{*}{$\mathrm{H}$} & \multirow[b]{2}{*}{ St } & \multicolumn{4}{|c|}{ Warna pada kantong } & \multirow[b]{2}{*}{$\mathrm{Cr}$} & \multirow[b]{2}{*}{ Sy } & \multirow[b]{2}{*}{$\mathrm{R}$} & \multirow[b]{2}{*}{$\mathrm{Tk}$} \\
\hline & & & Badan & Sayap & Bibir & Tutup & & & & \\
\hline \multirow{4}{*}{ N. gracilis } & & $\mathrm{ka}$ & $\mathrm{hk}, \mathrm{hm}, \mathrm{m}$ & - & $\mathrm{hk}, \mathrm{hm}, \mathrm{m}$ & $\mathrm{hk}, \mathrm{hm}, \mathrm{m}$ & - & - & - & $\mathrm{P}$ \\
\hline & $\mathrm{K}$ & $\mathrm{kb}$ & $\mathrm{hk}, \mathrm{hm}, \mathrm{m}$ & $\mathrm{hk}, \mathrm{hm}, \mathrm{m}$ & $\mathrm{hk}, \mathrm{hm}, \mathrm{m}$ & $\mathrm{hk}, \mathrm{hm}, \mathrm{m}$ & - & $\sqrt{ }$ & $\sqrt{ }$ & $\mathrm{P}$ \\
\hline & $\mathrm{B}$ & $\mathrm{ka}$ & $\mathrm{hk}, \mathrm{hm}, \mathrm{m}$ & - & $\mathrm{hk}, \mathrm{hm}, \mathrm{m}$ & $\mathrm{hk}, \mathrm{hm}, \mathrm{m}$ & - & - & - & $\mathrm{P}$ \\
\hline & $\mathrm{B}$ & $\mathrm{kb}$ & $\mathrm{hk}, \mathrm{hm}, \mathrm{m}$ & $\mathrm{hk}, \mathrm{hm}, \mathrm{m}$ & $\mathrm{hk}, \mathrm{hm}, \mathrm{m}$ & $\mathrm{hk}, \mathrm{hm}, \mathrm{m}$ & - & $\sqrt{ }$ & $\sqrt{ }$ & $\mathrm{P}$ \\
\hline \multirow{4}{*}{ N. rafflesiana } & & $\mathrm{ka}$ & hkbm & - & hkbm & hkbm & $\sqrt{ }$ & - & - & $\mathrm{P}$ \\
\hline & K & $\mathrm{kb}$ & hkbm & hkbm & hkbm & hkbm & $\sqrt{ }$ & $\sqrt{ }$ & - & $\mathrm{P}$ \\
\hline & & $\mathrm{ka}$ & hkbm & - & hkbm & hkbm & $\sqrt{ }$ & - & - & $\mathrm{P}$ \\
\hline & B & $\mathrm{kb}$ & hkbm & hkbm & hkbm & hkbm & $\sqrt{ }$ & $\sqrt{ }$ & $\sqrt{ }$ & $\mathrm{P}$ \\
\hline \multirow{4}{*}{ N. ampullaria } & & $\mathrm{ka}$ & hkbm & hkbm & hkbm & hkbm & $\sqrt{ }$ & $\sqrt{ }$ & $\sqrt{ }$ & $\mathrm{TP}$ \\
\hline & $\mathrm{K}$ & $\mathrm{kb}$ & hkbm & hkbm & hkbm & hkbm & $\sqrt{ }$ & $\sqrt{ }$ & $\sqrt{ }$ & $\mathrm{TP}$ \\
\hline & $\mathrm{R}$ & $\mathrm{ka}$ & hkbm & hkbm & hkbm & hkbm & $\sqrt{ }$ & $\sqrt{ }$ & $\sqrt{ }$ & $\mathrm{TP}$ \\
\hline & B & $\mathrm{kb}$ & hkbm & hkbm & hkbm & hkbm & $\sqrt{ }$ & $\sqrt{ }$ & $\sqrt{ }$ & $\mathrm{TP}$ \\
\hline
\end{tabular}

Keterangan: H: habitat; K: kering; B: basah; St: status; ka: kantong atas; kb:kantong bawah; hk hijau kuning; hm: hijau merah; hkbm: hijau kuning bercak merah; m: merah; Cr: corak; Sy: sayap; R: renda; Tk: tutup kantong; $\sqrt{\text { : }}$ memiliki; -: tidak memiliki; P: proporsional; TP: tidak proporsional.

Kantong $N$. rafflesiana memiliki ukuran yang lebih besar dari jenis lain yang ditemukan dilokasi penelitian (Tabel 6). Penelitian Maysarah et al. (2016) menunjukkan bahwa ukuran kantong di hutan kerangas lebih kecil dibandingkan di hutan rawa gambut. Hal ini diduga bahwa kondisi hutan kerangas memiliki suhu yang lebih tinggi dibandingkan dengan hutan gambut, sehingga Nepenthes spp. memperkecil ukurannya untuk mengurangi kehilangan air.

\section{c. Variasi batang dan sulur}

Panjang batang $N$. gracilis termasuk paling tinggi dibandingkan dengan $N$. ampullaria dan $N$. rafflesiana. Hal ini diduga karena $N$. gracilis tumbuh tinggi memanjat pohon. Panjang sulur dan posisi sulur sangat bervariasi, $N$. rafflesiana memiliki ukuran sulur lebih panjang dari ketiga jenis yang ditemukan. Ukuran sulur yang panjang bertujuan untuk menopang kantong. Posisi sulur dari kantong bawah hingga menuju kekantong atas berawal dari depan mulut kantong hingga menyamping dan pada kantong paling atas posisi sulur membelakangi mulut kantong (Tabel 7). Posisi sulur dari kantong bawah semakin ke kantong atas ternyata memutar dari depan kesamping kemudian kebelakang (Handayani dan Astuti 2005). Handayani et al. (2005) menjelaskan bahwa sulur muncul dari ujung daun sebagai penopang kantong agar tetap tegak, oleh karena itu sulur kantong atas harus kuat karena harus menopang kantong yang menggantung. 
Tabel 6 Ukuran kantong Nepenthes spp

\begin{tabular}{|c|c|c|c|c|}
\hline Spesies & Habitat & Status & Panjang $(\mathrm{cm})$ & Diameter $(\mathrm{cm})$ \\
\hline \multirow{4}{*}{ N. gracilis } & \multirow{2}{*}{ K } & $\mathrm{ka}$ & 11,2 & 2,1 \\
\hline & & $\mathrm{kb}$ & 7,8 & 1,9 \\
\hline & \multirow{2}{*}{ B } & $\mathrm{ka}$ & 8,6 & 1,6 \\
\hline & & $\mathrm{kb}$ & 7,8 & 1,7 \\
\hline \multirow{4}{*}{ N. rafflesiana } & \multirow{2}{*}{$\mathrm{K}$} & $\mathrm{ka}$ & 19,6 & 3,4 \\
\hline & & $\mathrm{kb}$ & 12,6 & 3,3 \\
\hline & \multirow{2}{*}{ B } & $\mathrm{ka}$ & 22,2 & 3,1 \\
\hline & & $\mathrm{kb}$ & 17,1 & 4,4 \\
\hline \multirow{4}{*}{ N. ampullaria } & \multirow{2}{*}{$\mathrm{K}$} & $\mathrm{ka}$ & 11,8 & 3,1 \\
\hline & & $\mathrm{kb}$ & 4,2 & 3,6 \\
\hline & \multirow{2}{*}{ B } & $\mathrm{ka}$ & 10,3 & 3,3 \\
\hline & & $\mathrm{kb}$ & 3,4 & 3,2 \\
\hline
\end{tabular}

Keterangan: K: kering; B: basah; ka: daun kantong atas; kb: daun kantong bawah.

Tabel 7 Variasi panjang batang, diameter batang, panjang sulur dan posisi sulur

\begin{tabular}{|c|c|c|c|c|c|c|c|c|c|}
\hline \multirow{3}{*}{ Spesies } & \multirow{3}{*}{ Habitat } & \multirow{3}{*}{ Status } & \multirow{2}{*}{\multicolumn{3}{|c|}{ Batang }} & \multicolumn{4}{|c|}{ Sulur } \\
\hline & & & & & & \multirow[b]{2}{*}{ PS $(\mathrm{cm})$} & \multicolumn{3}{|c|}{ Posisi } \\
\hline & & & $\mathrm{BB}$ & $\begin{array}{l}\text { PB } \\
(\mathrm{cm})\end{array}$ & $\begin{array}{c}\text { DB } \\
(\mathrm{mm})\end{array}$ & & B & $\mathrm{S}$ & $\mathrm{D}$ \\
\hline \multirow{4}{*}{ N. gracilis } & \multirow{2}{*}{$\mathrm{K}$} & $\mathrm{ka}$ & segitiga & 393 & 7,9 & 15,3 & $\sqrt{ }$ & - & - \\
\hline & & $\mathrm{kb}$ & segitiga & 44 & 7,2 & 6,0 & - & - & $\sqrt{ }$ \\
\hline & \multirow{2}{*}{ B } & $\mathrm{ka}$ & segitiga & 550 & 7,0 & 10,9 & $\sqrt{ }$ & $\sqrt{ }$ & - \\
\hline & & $\mathrm{kb}$ & segitiga & 133 & 7,6 & 4,3 & - & $\sqrt{ }$ & $\sqrt{ }$ \\
\hline \multirow{4}{*}{ N. rafflesiana } & \multirow{2}{*}{$\mathrm{K}$} & $\mathrm{ka}$ & silinder & 242 & 8,1 & 30,5 & $\sqrt{ }$ & - & $\sqrt{ }$ \\
\hline & & $\mathrm{kb}$ & silinder & 99 & 8,1 & 45,0 & - & - & $\sqrt{ }$ \\
\hline & \multirow{2}{*}{ B } & ka & silinder & 263 & 7,7 & 29,0 & $\sqrt{ }$ & - & - \\
\hline & & $\mathrm{kb}$ & silinder & 64 & 7,8 & 34,3 & - & - & $\sqrt{ }$ \\
\hline \multirow{4}{*}{ N. ampullaria } & \multirow{2}{*}{$\mathrm{K}$} & $\mathrm{ka}$ & silinder & 376 & 7,7 & 5,0 & - & - & $\sqrt{ }$ \\
\hline & & $\mathrm{kb}$ & silinder & 48 & 8,5 & 1,0 & - & - & $\sqrt{ }$ \\
\hline & \multirow{2}{*}{ B } & ka & silinder & 194 & 7,9 & 6,8 & - & - & $\sqrt{ }$ \\
\hline & & $\mathrm{kb}$ & silinder & 63 & 8,0 & 1,6 & - & - & $\sqrt{ }$ \\
\hline
\end{tabular}

Keterangan: K: kering; ka: kantong atas; kb:kantong bawah; B: basah; BB: bentuk batang; PB: panjang batang; DB: diameter batang; PS: panjang sulur; B: belakang; S: samping; D: depan; $\sqrt{ }$ : memiliki; -: tidak memiliki.

\section{Pertelaan Nepenthes spp.}

\section{a. Nepenthes gracilis Korth}

Posisi daun duduk dan memeluk batang, tidak memiliki tangkai daun, ujung dan pangkal daun runcing, bentuk daun lanset, permukaan daun mengkilap, tepi daun rata, daun bawah memiliki panjang 7,1-11,5 cm, lebar 1,6-22 cm, tebal 2,3-3,1 mm, daun fertil berjumlah 3-7, daun steril berjumlah 1-3, warna permukaan dan tulang primer umumnya hijau kekuningan. Ukuran panjang daun atas 12,5-15,5 cm, lebar 1,6-4,4, tebal 2,6$3,1 \mathrm{~mm}$, daun fertil berjumlah 6-15, daun steril berjumlah 12-28, warna permukaan dan tulang daun primer umumnya hijau kekuningan. Kantong bawah memiliki ukuran panjang 6,5-9,1 cm, diameter 1,7-1,9, kantong berbentuk kendi gentong dan atau kendi leher panjang, peristom bergerigi kecil, warna badan hijau kekuningan atau merah, warna sayap merah, warna bibir kantong hijau kekuningan atau merah, warna tutup hijau kekuningan atau merah, kantong ada yang bercorak berupa bintik merah dan tak bercorak, bersayap dan ber- renda, tutup kantong proporsional. Kantong atas memiliki panjang 8,2-12,3 cm, diameter $1,5-2,4 \mathrm{~cm}$, kantong berbentuk kendi leher panjang, warna badan, warna bibir dan warna tutup kantong umumnya hijau kekuningan, tidak bersayap, warna kantong bervariasi yaitu merah, hijau, coklat, bentuknya silinder di bagian atas dan bulat telur di bagian bawah, peristom berwarna hijau, tutup kantong berwarna hijau, tutup kantong proporsional, sulur kantong atas memiliki panjang 10,7$18,0 \mathrm{~cm}$, posisi sulur membelakangi atau menyamping dari mulut kantong, berwarna hijau kekuningan, sulur kantong bawah memiliki panjang 3-6 cm, posisi sulur di depan atau menyamping, warna sulur hijau kekuningan atau merah coklat. Panjang batang $44-723 \mathrm{~cm}$, diameter 7,02-8,12 mm. Bentuk batang segitiga, warna batang merah kecoklatan atau hijau kekuningan. Bunga $N$. gracilis di lokasi penelitian tidak ditemukan. Mansur (2006) menambahkan bunga berbentuk tandan, berwarna coklat, panjang $\leq 25 \mathrm{~cm}$, sepal oval hingga lonjong, bunga betina kadang lebih panjang dari bunga jantan. Penelitian Kato (1993) tentang biologi bunga N. gracilis 
menunjukkan dalam satu bunga jantan terdapat 22-90 tunas bunga atau kuncup, sedangkan bunga betina sekitar 22-53 kuncup, proses mekarnya secara akropetal yaitu mekar bertahap dari bagian bawah hingga kuncup bunga paling muda (Gambar 1).

\section{b. Nepenthes rafflesiana Jack}

Daun berbentuk lanset memanjang, berupih, tangkai daun panjang, permukaan atas daun mengkilap hijau tua, tepi rata, panjang daun bawah 27,5-37,7 cm, lebar 4,36,7, tebal 2,9-3,4 mm, jumlah daun fertil 6-12, steril 518. Warna permukaan atas dan tulang primer atas hijau tua, warna permukaan bawah dan tulang primer bawah hijau muda kekuningan. Panjang daun atas 23,3-29,3 cm, lebar 4,0-5,1 cm, tebal 2,7-3,6 mm, jumlah daun fertil 611, steril 4-11, warna permukaan atas dan tulang primer atas hijau tua, warna permukaan bawah dan tulang primer bawah hijau muda kekuningan. Kantong bawah berbentuk gelas tambun, bersayap dan ber-renda, warna badan, sayap, bibir dan tutup kantong hijau kekuningan atau merah tua bercak-bercak, tutup kantong proporsional, panjang kantong bawah 11,7-17,2 cm, kantong atas 14,2-25,0 cm, diameter kantong bawah 3,14,4 cm, kantong atas 2,8-4,0 cm, kantong atas dan bawah ada yang memiliki bercak merah ungu, bersayap dan berrenda. Panjang sulur bawah 33-46 cm, sulur atas 29-36 $\mathrm{cm}$, berwarna hijau kekuningan, posisi sulur bawah di depan mulut kantong dan sulur atas didepan atau belakang mulut kantong. Panjang batang $34-324 \mathrm{~cm}$ berbentuk silinder atau bulat, diameter 7,65-8,12 mm berwarna hijau. Menurut Handayani et al. (2005) batang $N$. rafflesiana dapat tumbuh hingga 9 meter. Organ generatif berupa bunga. Bunga $N$. rafflesiana tidak ditemukan di lokasi penelitian. Mansur (2006) mendeskripsikan bunga berbentuk tandan dengan panjang $\leq 50 \mathrm{~cm}($ Gambar 2).

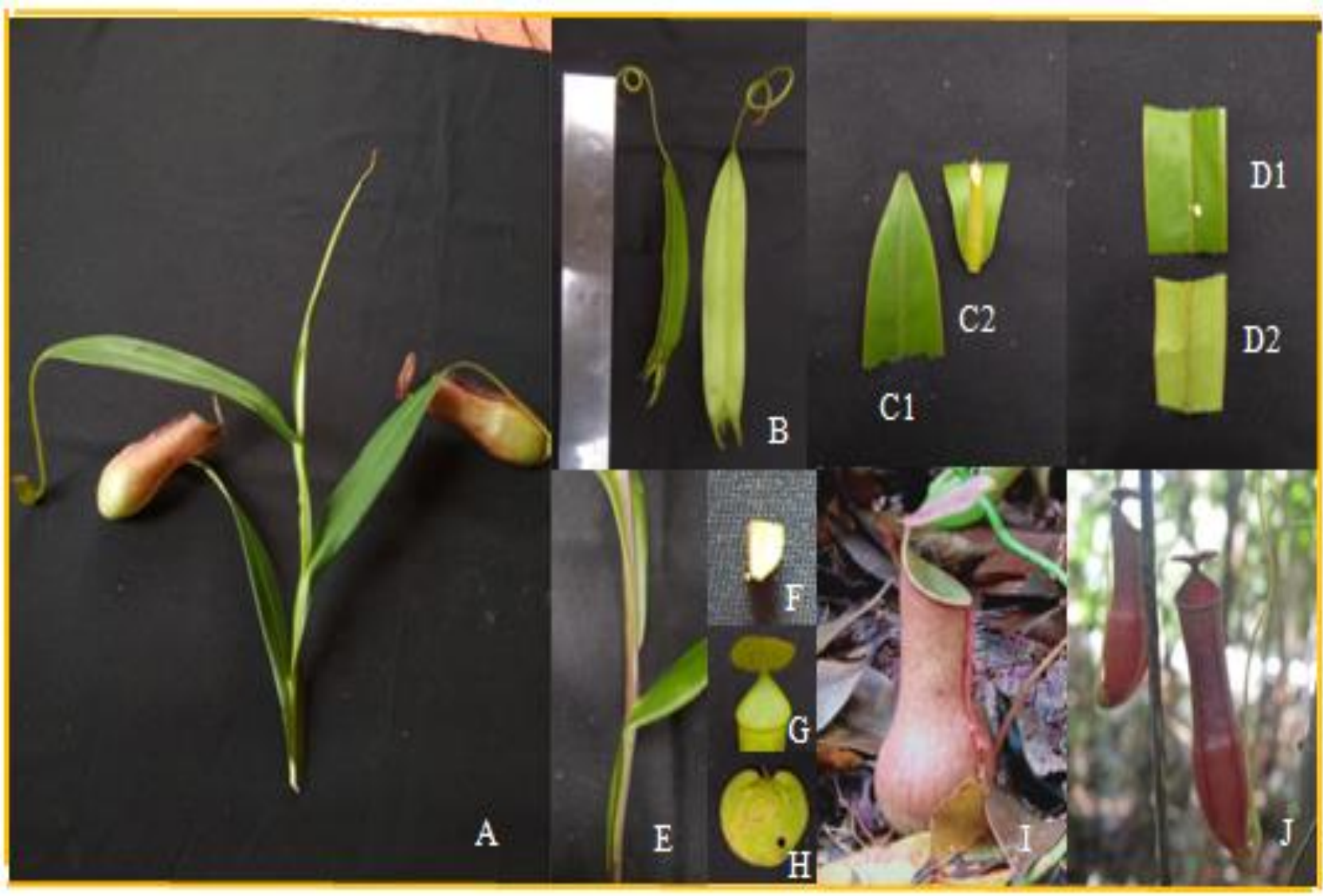

Gambar 1 Morfologi N. gracilis

Keterangan: A: susunan daun; B: helai daun; C1: ujung daun; C2: pangkal daun; D1: permukaan atas daun; D2: permukaan bawah daun; E: batang; F: penampang vertikal batang; G: mulut kantong; H: tutup kantong; I: kantong bawah; J: kantong atas. 


\section{c. Nepenthes ampullaria Jack}

Daun berbentuk lanset, berupih, tangkai daun pendek, tangkai dan permukaan daun bawah kadangkadang berbulu kecoklatan, tepi daun rata, pangkal dan ujung daun runcing. Panjang daun bawah 24,0-28,2 cm, lebar 5,3-6,9 cm, tebal 2,1 mm, jumlah daun fertil 1-2, steril 6-12, warna permukaan dan tulang primer hijau kekuningan. Panjang daun atas 29,8-33,8 cm, lebar 7,7$8,2 \mathrm{~cm}$, tebal 2,1-2,3 $\mathrm{mm}$, jumlah daun fertil 3-4, daun steril 19-37, warna permukaan dan tulang daun primer hijau kekuningan. Mulut kantong berbentuk lembaran seperti corong. Kantong bawah memiliki panjang 3,4-4,2 $\mathrm{cm}$, diameter 3,2-3,6 cm, bentuk kantong gelas tambun, warna badan dan sayap hijau kekuningan dengan bercak merah keunguan, warna bibir dan tutup hijau kekuningan, bersayap dan berenda, tutup kantong tidak proporsional. Panjang kantong atas 10,3-11,8 cm, diameter 3,1-3,3 cm, bentuk kantong gelas tambun, warna badan dan sayap hijau kekuningan dengan bercak merah keunguan, warna bibir dan tutup hijau kekuningan, bersayap dan berenda, tutup kantong tidak proporsional. Panjang sulur bawah 1,0-1,6 cm dan sulur atas 5,0-6,8 cm, berwarna hijau kekuningan, posisi sulur di depan mulut kantong. Panjang batang $48-376 \mathrm{~cm}$, diameter 7,65-8,00 mm, berwarna hijau kekuningan, berbentuk bulat atau silinder. Bunga $N$. ampullaria tidak ditemukan di lapangan. Mansur (2006) perbungaannya berbentuk malai, panjang $\leq 35 \mathrm{~cm}$, perbungaan betina lebih pendek dari bunga jantan. Bunga betina muda sering ditutupi bulu halus berwarna coklat, ukuran panjang kuncup bunga 6-30 $\mathrm{mm}$, lebar 2-6 mm, bunga jantan memiliki 4 sepal (Meriko 2012) (Gambar 3).

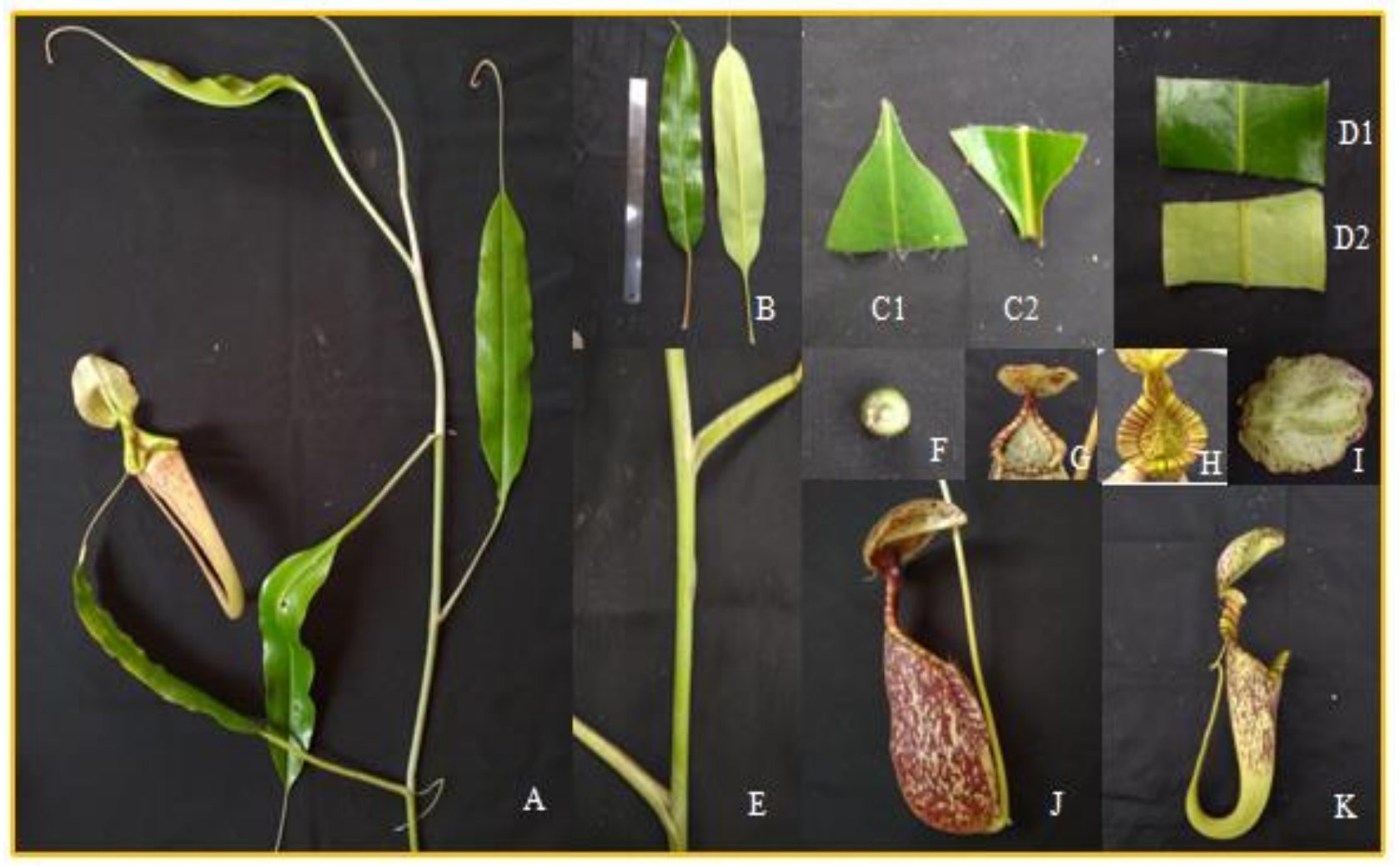

Gambar 2 Morfologi N. rafflesiana

Keterangan: A: susunan daun; B: helai daun; C1: ujung daun; C2: pangkal daun; D1: permukaan atas daun; D2: permukaan bawah daun; E: batang; F: penampang vertikal batang; G: mulut kantong bawah; H: mulut kantong atas; I: tutup kantong; J: kantong bawah; K: kantong atas. 


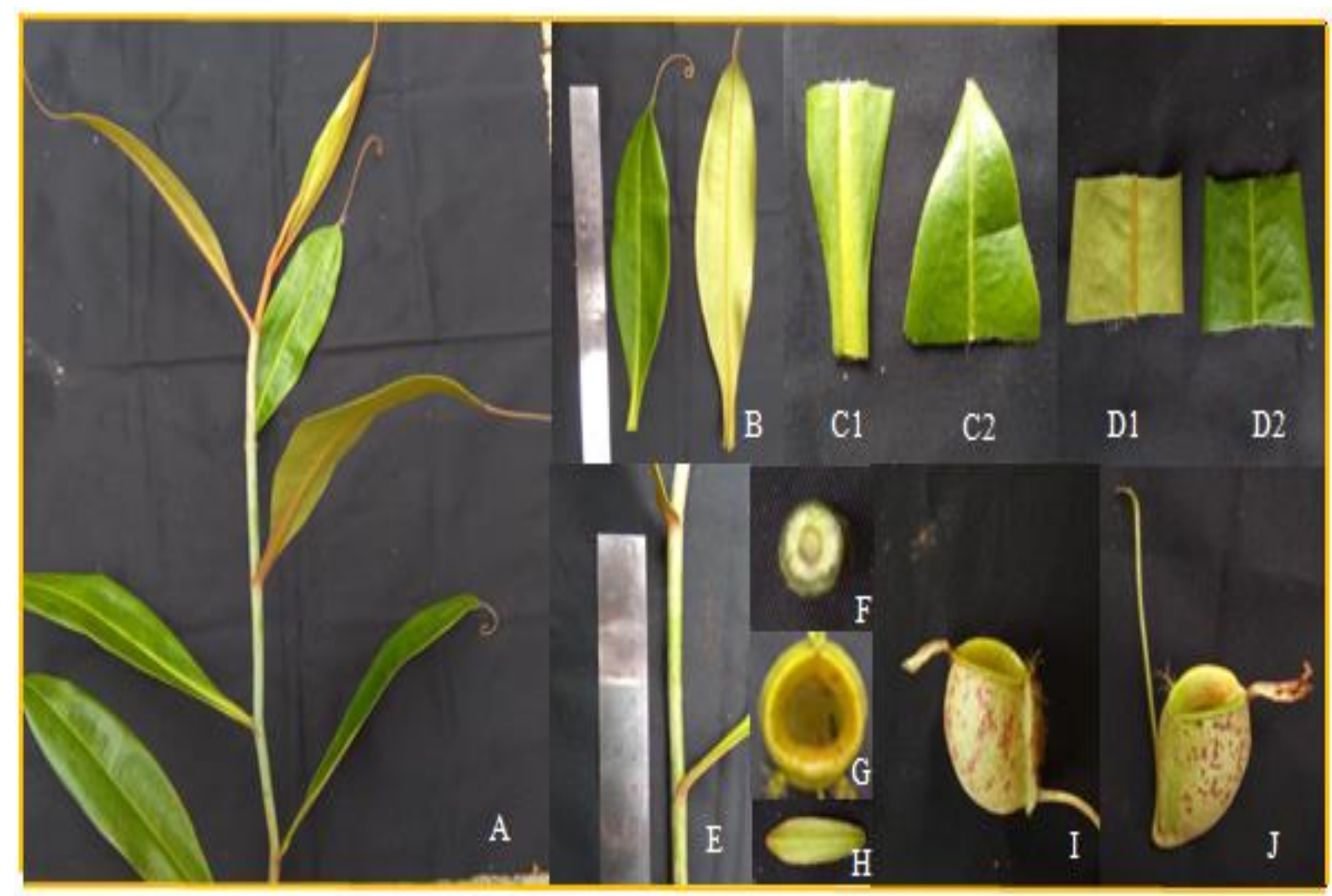

Gambar 3 Morfologi N. ampullaria

Keterangan: A: susunan daun; B: helai daun; C1: pangkal daun; C2: ujung daun; D1: permukaan bawah daun; D2: permukaan atas daun; E: batang; F: penampang vertikal batang; G: mulut kantong; H: tutup kantong; I: kantong bawah; J: kantong atas.

\section{SIMPULAN}

Jenis Nepenthes spp. yang ditemukan di Taman Keaneragaman Hayati Hutan Pelawan, Desa Namang yaitu Nepenthes gracilis Korth sebanyak 348 individu, Nepenthes rafflesiana Jack sebanyak 18 individu dan Nepenthes ampullaria Jack sebanyak 45 individu. Indeks keanekaragaman (H') tergolong rendah. Karakteristik fenotip jumlah daun steril berkisar 2-37 helai, daun fertil berkisar 1-12 helai, panjang daun berkisar 9,5-37,2 cm, lebar daun berkisar $1,7-8,2 \mathrm{~cm}$ dan tebal daun berkisar 2,1-3,5 mm. Panjang kantong berkisar 3,4-22,2 $\mathrm{cm}$ dan diameter kantong berkisar 1,6-4,4 cm. Variasi bentuk kantong yaitu bentuk kendi leher panjang, kendi gentong, terompet panjang, dan gelas tambun. Varasi warna kantong terdiri atas warna hijau kuning, hijau kuning bercak merah, hijau merah dan merah. Variasi corak kantong berupa bintik-bintik merah keunguan, sayap dan renda bervariasi, kantong atas bersayap dan berenda, tutup kantong terdiri atas bentuk proporsional dan tak proporsional. Panjang batang berkisar $44-550 \mathrm{~cm}$, diameter batang berkisar 7,0-8,5 $\mathrm{mm}$ dan panjang sulur berkisar 1,0-34,4 cm. Posisi sulur terdiri atas posisi membelakangi, menyamping dan di depan mulut kantong.

\section{DAFTAR PUSTAKA}

Alfionita T. 2018. Variasi morfologi Nepenthes spp. di hutan Dusun Air Pasir, Desa Lampur, Kecamatan Sungaiselan, Kabupaten Bangka Tengah [skripsi]. Bangka: Universitas Bangka Belitung.

Cahyono DB, Roini C, Tamalene MN. 2019. Karakterisasi habitat tumbuhan kantong semar (Nepenthes spp.) di Pulau Halmahera. Jurnal Techno. $8(1): 233-240$

Devilia. 2018. Variasi morfologi Nepenthes spp. di Kawasan Padang Sapu-Sapu, Dusun Pejem, Desa Gunung Pelawan, Kabupaten Bangka [skripsi]. Bangka: Universitas Bangka Belitung.

Ginting N, Lubis JA. 2017. Inventarisasi Nepenthes di Tapanuli Selatan. Biolink. 3(2):183-193

Gultom RJ, Fahrizal, Idham M. 2015. Studi keanekaragaman jenis kantong semar (Nepenthes spp.) di Kawasan Konservasi Rumah Pelangi Dusun Gunung Benuah Kecamatan Sungai Ambawang Kabupaten Kubu Raya. Jurnal Hutan Lestari. 3(4): 184-191.

Gusdiarto, Astiani D, Herawatiningsih R. 2018. Keanekaragaman jenis dan kondisi tempat tumbuh 
kantong semar (Nepenthes spp.) di Kawasan Hutan Gunung Selindung Desa Twi Mentibar Kecamatan Selakau Kabupaten Sambas. Jurnal Hutan Lestari. 6(2):371-385.

Handayani T, Astuti IP. 2005. Perilaku tumbuh kantong semar (Nepenthes mirabilis Druce) di habitat alaminya, Taman Nasional Kutai, Kalimantan Timur. Biosfera. 22(3):213-220.

Handayani T, Latifah D, Dodo. 2005. Diversity and growth behaviour of Nepenthes (Pitcher Plants) in Tanjung Puting National Park, Central Kalimantan Province. Biodiversitas. 6(4):248-252.

Handoyo, Sitanggang. 2006. Perawatan Praktis Kantong Semar. Jakarta: PT. Grafindo Persada.

Jeeb M, Cheeck M. 2001. Nepenthaceae. Flora Malasiana.15(1):1-157.

Kato M. 1993. Floral biologi of Nepenthes gracilis (Nepenthaceae) from Sumatra. American Journal of Botany. 80(8):924-927.

Kissinger. 2013. Bioprospeksi hutan kerangas: Analisis Nepenthes gracilis Korth sebagai stimulus konservasi [disertasi]. Bogor: Institut Pertanian Bogor.

Mansur M. 2006. Nepenthes spp. Kantong Semar Unik. Jakarta: Penebar Swadaya.

Mansur M. 2008. Penelitian ekologi Nepenthes di Laboratorium Alam Hutan Gambut Sebangau Kereng Bangkirai Kalimantan Tengah. Jurnal Teknik Lingkungan. 9(1): 67-73.

Mansur M. 2012. Laju penyerapan $\mathrm{CO}_{2}$ pada kantong semar (Nepenthes gymnamphora Nees) di Taman Nasional Halimun Salak, Jawa Barat. Jurnal Teknik Lingkungan. 13(1):59-65.

Maysarah, Zuhud EA, Hikmat A. 2016. Populasi dan habitat Nepenthes ampullaria Jack. di Cagar Alam
Mandor, Kalimantan Barat. Media Konservasi. 21(2): 125-134.

Meriko L. 2012. Biologi bunga tumbuhan Nepenthes. Jurnal Pelangi. 4(2):66-75.

Mulyanto H, Cahyuningdari D, Setiawan AD. 2000. Kantung semar (Nepenthes sp.) di Gunung Merbabu. Biodiversitas. 1(2):54-58.

Odum EP. 1993. Ekologi Sistem. Terjemahan Supriharyono. Yogyakarta: Gadjah Mada University Press.

Rizqiani. 2018. Keanekaragaman kantong semar (Nepenthes) di Kepulauan Bangka Belitung [tesis]. Bogor: Institut Pertanian Bogor.

Sartika. 2017. Population and distribution pattern kantong semar (Nepenthes gracilis) in Rhino Camp Resort Sukaraja Atas Region Bukit Barisan Selatan Nasional Park (BBSNP). Jurnal Siylva Lestari. 5(3):12-21.

Selviana A, Turnip R, Linda R. 2018. Variasi morfometrik dan pengelompokan spesies kantong semar (Nepenthes spp.) di Desa Simpang Kasturi Kecamatan Mandor. Protobiont. 7(2):29-36.

Setiawan H. 2013. Inventarisasi Nepenthes di Hutan Adat Katuk dan implementasinya berupa Buku Saku Keanekaragaman Hayati Indonesia [artikel penelitian]. Pontianak: Universitas Tanjung Pura.

Syamsi F, Sudirman D. 2017. Keanekaragaman kantong semar (Nepenthes spp.) di Pulau Batam. Jurnal Dimensi. 2(3):442-452.

Zakaria A, Manurung TF, Sisillia L. 2016. Keanekaragaman jenis kantong semar (Nepenthes spp.) dalam Kawasan Hutan Lindung Gunung Semahung Desa Saham Kecamatan Sengah Temila Kabupaten Landak. Jurnal Hutan Lestari. 4(4):204208. 